\title{
A intervenção da censura comunista em traduções romenas de literatura portuguesa: o romance "Os Maias" de Eça de Queirós
}

\author{
Veronica MANOLE \\ Universidade Babeș-Bolyai; Cluj-Napoca \\ Rumania
}

\begin{abstract}
Resumo: Este artigo faz uma análise sucinta das intervenções da censura comunista na tradução em romeno do romance Os Maias de Eça de Queirós. A comparação das versões de 1978 e de 2005 com o texto original revela apenas algumas intervenções em fragmentos que tratam questões políticas. A maioria das alterações na edição de 1978 - substituições de palavras, supressões totais ou parciais de texto - ocorre em fragmentos sobre a relação incestuosa entre os protagonistas. Esta análise mostra como o tradutor, sem querer, foi transformado em traidor durante o regime comunista romeno.
\end{abstract}

Palavras chave : censura comunista romena, tradução literária, literatura portuguesa, tradução romena, Eça de Queirós

\begin{abstract}
This article briefly analyses the interventions of the communist censorship in the Romanian translation of the novel Os Maias [The Maias] by Eça de Queirós. A comparison of the 1978 and the 2005 editions with the original text shows only a few interventions in fragments that tackle political issues. Most of the changes that we identified in the 1978 edition - word replacement, total or partial textual omission - occur in fragments about the incestuous relationship between the main characters. This analysis shows how the translator unwillingly turned into a traitor during the Romanian communist regime.
\end{abstract}

Keywords: Romanian communist censorship, literary translation, Portuguese literature, Romanian translation, Eça de Queirós

\section{Introdução}

Numa história - ainda por escrever - das traduções romenas de literatura portuguesa, a influência da censura comunista e os constrangimentos decorrentes da sua atuação mereceriam um estudo aprofundado. Neste trabalho limitar-nos-emos a descrever um estudo de caso, a tradução em romeno do romance Os Maias de Eça de Queirós, que poderia servir de exemplo para análises mais pormenorizadas. 
Em primeiro lugar, queremos fazer algumas cosiderações gerais sobre a censura durante a época comunista na Roménia. Direcţia Generală a Presei şi Tipăriturilor ${ }^{1}$ [Direção Geral da Imprensa e das Impressões], a face institucional da censura comunista, funcionou na Roménia entre 1949 e 1977, sendo os censores transferidos ulteriormente para Consiliul Culturii şi Educaţiei Socialiste [Conselho da Cultura e da Educação Socliasita]. Havia censores em outras instituições também, como Uniunea Scriitorilor din România [União dos Escritorea da Roménia], Securitatea [Segurança] - órgão de repressão parecido com a PIDE , Secţia de Propagandă şi Agitaţie [Secção de Propaganda e Agitação] do Partido Comunista Romeno (Corobca 2013).

No Raport final [Relatório final] da Comisia Prezidenţială pentru Analiza Dictaturii Comuniste din România [Comissão Presidencial para a Análise da Ditadura Comunista da Roménia], cujo presidente foi Vladimir Tismăneanu, faz-te uma síntese dos objetivos da censura:

"Tradiţia culturală a fost reinterpretată în conformitate cu noile dogme: principalele personalităţi din literatura română au fost eliminate din publicaţiile oficiale, cenzura a fost aplicată drastic pentru a elimina orice aducea a 'naţionalism', 'cosmopolitism', 'obiectivism' sau alte forme de 'decadenţă burgheză”' (Tismăneanu 2006, 50).

[A tradição cultural foi reinterpretada de acordo com os novos dogmas: as personalidades principais da literatura romena foram eliminadas das publicações oficiais, a censura foi aplicada de forma drástica para eliminar qualquer alusão a "nacionalismo", "cosmopolitanismo", "objectivismo" ou a outras formas de "decadência burguesa ${ }^{2 "]}$ (Nossa tradução).

$\mathrm{Na}$ tradução de literatura estrangeira, mantinham-se os mesmos padrões de censura que se adotavam no caso dos escritores romenos; aliás, Rădulescu (2011) e Vida (2011) descrevem como funcionava a censura em traduções de literatura infantil francesa ou do romance Madame Bovary. Por conseguinte, fragmentos que tratavam ou faziam alusão a assuntos rejeitados pela ideologia do momento - a religião, a ditadura, o exílio, mas também questões de costumes, como a sexualidade - eram quer eliminados por completo, quer "suavizados" ou "edulcorados" pelos censores.

Um dos exemplos mais evidentes da influência da censura sobre as traduções de literatura portuguesa é a alteração dos títulos

${ }^{1} \mathrm{O}$ modelo usado na criação desta instituição era o Glavlit soviético (Corobca 2012).

${ }^{2}$ A "decadência burguesa" incluía modas e costumes vindos do Ocidente, sobretudo relacionados com a vida social. Por exemplo, assuntos como a sexualidade fora do casamento eram um exemplo de comportamento decadente. 
das obras, sendo o romance de José Saramago $O$ memorial do convento um caso exemplar: como convento era claramente uma palavra religiosa, a edição romena de 1988 recebeu o título Memorialul de la Mafra [O memorial de Mafra]. Mafra, referência cultural desconhecida e, por conseguinte, palavra inofensiva do ponto de vista dos censores, foi a solução encontrada para se conseguir publicar uma obra possivelmente "perigosa". Mas este caso não é singular. Em Ghițescu (1995, 55-58) e em Ghițescu (2012, 139146) mencionam-se outros exemplos de alterações de títulos considerados inadequados pelos censores: Exílio perturbado [Exil perturbat] de Urbano Tavares Rodrigues tornou-se Șfirșit de exil [Fim de exílio] em 1987, Silêncio para 4 [Liniște pentru 4] de Ruben A. foi transformado em Singurătate în patru [Solidão em quatro] em 1990. A alteração dos títulos era apenas um dos mecanismos da intervenção da censura, sendo práticas comuns tanto a intervenção direta no texto - a eliminação de algumas frases ou de páginas inteiras -, como a proibição total de livros inteiros ou de autores.

Em alguns casos, foi possível publicar depois da Revolução de 1989 edições integrais de livros previamente censurados, mas nem todas as traduções de obras portuguesas tiveram este destino. Infelizmente, ficaram conhecidas na Roménia apenas nas suas versões mutiladas. Por exemplo, o romance $O$ que diz Molero de Dinis Machado tem duas edições em romeno: a primeira, de 1981, contém intervenções massivas dos censores - sobretudo em trechos sobre a vida sexual das personagens -, ao passo que a segunda edição, publicada 2005, é integral. Nesta segunda edição, os fragmentos eliminados foram introduzidos entre colchetes, podendo assim o leitor observar como trabalhava a censura comunista romena. O romance Os Maias de Eça de Queirós é também um dos exemplos felizes, com duas versões em romeno, publicadas em 1978 (censurada) e em 2005 (integral), que constituem o corpus desta análise.

Vejamos, num primeiro momento, um levantamento das obras de Eça de Queirós traduzidas em romeno.

\section{Eça de Queirós em romeno}

A primeira tradução romena de uma obra de Eça de Queirós3 foi publicada em 1968; trata-se do romance $O$ crime do padre Amaro

3 Ghițescu (2000, 249) menciona traduções anteriores, dos contos $O$ defunto e $O$ tesouro (tradução do espanhol e não do português), ou de fragmentos do romance $O$ mandarim, publicadas na década dos anos '20. Mais recentemente, Cristina Petrescu publicou nas revistas culturais romenas Steaua, Apostrof, Mozaicul, EgoPHobia traduções de poemas de Fradique Mendes, o heterónimo coletivo em 
[Crima părintelui Amaro] traduzido por Micaela Ghițescu. Seguiram outras obras publicadas pela mesma tradutora: A relíquia [Relicva] em 1972, Os Maias [Familia Maia] em 1978 (e em 2005), O primo Basílio [Vărul Bazilio] em 1983. Mioara Caragea publicou em 1987 a tradução do romance $A$ cidade e a serra [Orașul și muntele]. Portanto, as obras principais de Eça de Queirós já são dỉsponíveis ao leitores romenos, mas, na nossa opinião, as reedições seriam extremamente úteis. Sobretudo no caso d'O crime do patre Amaro [Crima părintelui Amaro], obra que se encontra com dificuldade quer nas bibliotecas, quer nos alfarrabistas - a tradução foi publicada em 1968, há quase cinco décadas -, uma reedição acompahada por um estudo crítico seria oportuna.

Na próxima secção apresentamos algumas considerações de Micaela Ghițescu sobre as duas edições romenas d'Os Maias [Familia Maia].

\section{Os Maias: o testemunho da tradutora}

A edição integral d'Os Maias, publicada em 2005 pela Universal Dalsi, começa com uma nota da tradutora, que reproduzimos na íntegra:

"În legătură cu prezenta ediție, se cuvine să fac următoarea precizare: față de versiunea apărută în 1978 la Editura Univers din București, actuala traducere este integrală, cuprinzând toate pasajele pe care pudibonda cenzură comunistă - cu bine cunoscuta ei lipsă de scrupule față de autori și cititori - le-a eliminat. Am astăzi satisfacția profesională și bucuria de iubitor de literatură de a prezenta capodopera queiroziană în forma în care a pus-o pe hârtie marele romancier portughez."

"No que diz respeito à edição atual, acho justo fazer o esclarecimento seguinte: em relação à versão publicada em 1978 pela editora Univers de Bucareste, a tradução atual é integral e contém todos os trechos que a pudibunda censura comunista - com a sua conhecida falta de escrúpulos perante autores e leitores eliminou. Tenho hoje a satisfação profissional e a alegria de amante de literatura de apresentar a obra prima queirosiana na forma em que foi escrita pelo grande romancista português." (nossa tradução).

Ghițescu $(2012,142)$ afirma que os fragmentos que referiam explicitamente a relação incestuosa dos dois protagonistas foram "edulcorados"; em Ghițescu (2000, 257), a mesma autora menciona

que Eça de Queirós participou, com outros escritores conhecidos da mesma geração, como Antero de Quental, Guerra Junqueiro, Teófilo Braga e Ramalho Ortigão. 
"a eliminação de toda a passagem onde se tornava óbvia a consumação do incesto”.

A edição 1978 tem ainda um posfácio redigido pela tradutora, mantido na edição de 2005, com poucas alterações, também esclarecedoras no que diz respeito aos constrangimentos impostos pelas instituições de censura durante a época comunista. Entre as supressões de conteúdo, encontramos trechos que faziam referência explícita à ideologia comunista:

"Despre Comedia umană a lui Balzac, Engels spunea că ea valora mai mult, ca sursă de date asupra vieții din Franța între anii 1816 și 1848, decît toate compendiile istoricilor, economiștilor și statisticienilor profesioniști ai epocii.” (FM 1978, 682)

"Sobre Comédia humana de Balzac, Engels dizia que enquanto fonte de informação sobre a vida em França entre 1816 e 1848, a mesma valia mais do que todos os compêndios dos historiadores, dos economistas e dos estatísticos profissionais da época." (nossa tradução)

Na secção seguinte debruçar-nos-emos sobre a análise comparativa das duas versões, salientando as intervenções dos censores comunistas.

\section{Intervenções da censura: análise das duas edições}

Ao compararmos as edições de 1978 e de 2005 da tradução romena d'Os Maias, identificámos não apenas diferenças que advêm do modus operandi da censura na primeira versão, mas também intervenções da tradutora, que emendou erros iniciais, fez reformulações estilísticas e adaptações da grafia romena (em conformidade com as normas ortográficas adotadas em 1993 pela Academia Romena). Identificámos também uma intervenção no caso dos topónimos, traduzidos em romeno na versão de 1978 e mantidos na forma original na versão de 2005 .

Vejamos com mais atenção apenas as diferenças que são resultado do trabalho dos censores. Do ponto de vista temático, as intervenções mais importantes têm como objetivo edulcorar ou eliminar fragmentos em que Eça de Queirós refere de forma explícita a relação incestuosa entre os dois protagonistas, Carlos da Maia e Maria Eduarda. Aliás, suavizar as cenas de amor físico era uma estratégia comum durante o comunismo, como mostra também um estudo sobre a tradução do romance Ulisses de James Joyce (Ionescu 2010). Identificámos também na análise da tradução d'Os Maias intervenções da censura que incidem sobre trechos possívelmente prejudicantes para o regime político, mas são menos frequentes. 


\section{Edulcorações}

Uma das estratégias identificadas - mencionada também em Ghițescu (1999, 171-174) e Ghițescu (2012, 139-146) - é a atenuação de questões tabu, neste caso, o amor de Carlos da Maia e Maria Eduarda. As palavras explícitas são substituídas por hiperónimos, păcătoasă [pecadora] em vez de incestuoasă [incestuosa] em (1) ou por termos de campos lexicais diferentes dovadă oribilă [prova horrível] em vez de dovadă de incest [prova de incesto] em (2); usam-se também eufemismos, como o iubesc [amo-a] em vez de mă culc cu ea [durmo com ela] em (3) e frați și surori care intră în asemenea încurcături [irmão e irmãs que se metem em tais sarilhos] em vez de frați și surori care se culcă unï cu alții [irmãos a dormir juntos] em (4).

(1) "Poderia ele, tranquilamente, testemunhar a vida dos dois desde que a sabia «incestuosa»? (OM 2005 [1888], 633) // Va putea el, în liniște, să fie martorul vieții celor doi, de vreme ce o știa „păcătoasă”? (FM 1978, 587) // Va putea el, în liniște, să fie martorul vieții celor doi, de vreme ce o știa „incestuoasă”? (FM 2005, 585)

(2) Que coisa mais impiedosa, de resto, que estragar a vida de duas inocentes e adoráveis criaturas, atirando-lhes à face uma prova de incesto!..." (OM 2005 [1888], 632) // C"e putea fi mai necruțător, dealtfel (sic!), decît să strivești viața a două făpturi nevinovate și dragi, aruncîndu-le în obraz o dovadă oribilă?!...” [FM 1978, 586] // "Ce putea fi mai necruțător, dealtfel (sic!), decît să strivești viața a două făpturi nevinovate şi dragi, aruncîndu-le în obraz o dovadă de incest... "[FM 2005, 585]

(3) "Encontro uma mulher, olho para ela, conheço-a, durmo com ela e, entre todas as mulheres do mundo, essa justamente há-de ser minha irmã!" (OM 2005 [1888], 652) // "Întâlnesc o femeie, mă uit la ea, fac cunoștință cu ea, o iubesc, și dintre toate femeile din lume tocmai ea trebuie să fie sora mea!" (FM 1978, 605) // "Întâlnesc o femeie, mă uit la ea, fac cunoștință cu ea, mă culc cu ea, și dintre toate femeile din lume, tocmai ea trebuie să fie sora mea!" (FM 2005, 604)

(4) "Todos vocês acreditam, como se isto fosse a coisa mais natural do mundo, e não houvesse por essa cidade fora senão irmãos $a$ dormir juntos!" (OM 2005 [1888], 652) // "Voi toți credeți, ca și cum ar fi lucrul cel mai firesc din lume, și n-ar exista în orașul acesta decît frați și surori care intră în asemenea încurcături!” (FM 1978, 605) // "Voi toți credeți, ca și cum ar fi lucrul cel mai firesc din lume, și n-ar exista în orașul acesta decît frați şi surori care se culcă unii cu alții!! (FM 2005, 604) 


\section{Substituições}

Identificámos também um exemplo de intervenção por razões claramente ideológicos e políticos. No texto original, fala-se dos sindicatos e do papel dos mesmos no fenómeno de mercantilismo da sociedade portuguesa. Sendo esta afirmação possivelmente perigosa para a imagem do regime comunista, que usava bastante os sindicatos como instrumentos de propaganda e vigilância dos cidadãos, a tradução do termo português sindicatos pelo equivalente óbvio sindicatele foi substituída por societățile capitaliste [as sociedades capitalistas], como se pode observar em (5). A deturpação do significado é total: em vez de se criticar uma realidade de facto da sociedade portuguesa do fim do século XIX, o leitor pode identificar na personagem de Eça de Queirós um revolucionário comunista antes do tempo. Felizmente, na edição de 2005 esta intervenção foi devidamente alterada.

(5) "O novo Portugal só compreendia a língua da libra, da massa. Agora, filho, tudo eram sindicatos!” (OM 2005 [1888], 703) // "Noua Portugalie pricepea doar limba livrei, a fișicurilor de bani. Acum, fiule, totul sînt societățile capitaliste!” (FM 1978, 653) // "Noua Portugalie pricepea doar limba livrei, a fișicurilor de bani. Acum, fiule, totul sunt sindicatele!" (FM 2005, 653)

\section{Supressões parciais}

No caso deste romance, a estratégia mais utilizada pelos censores é a supressão de conteúdo, quer parcial, quer total. Por supressão parcial designamos eliminação de palavras, de trechos de frases ou de parágrafos, ao passo que a supressão total seria o corte integral de fragmentos de texto, às vezes páginas inteiras.

Vejamos alguns exemplos de supressões parciais que podem incidir sobre palavras tabu, como incesto em (6), mas também em fragmentos explícitos sobre a relação entre os dois irmãos, como em (7)-(10).

(6) "Mas, a esta ideia de «incesto", todas as consequências desse silêncio lhe apareceram, como coisas vivas e pavorosas, flamejando no escuro, diante dos seus olhos." (OM 2005 [1888], 633) // "Dar la gîndul acesta i-au apărut în fața ochilor, vii și înspăimîntătoare, toate consecințele acelei tăceri, ca niște flăcări în întuneric." (FM 1978, 587) // "Dar la gândul acesta de „incest” i-au apărut în fața ochilor, vii și înspăimîntătoare, toate consecințele acelei tăceri, ca niște flăcări în întuneric.” (FM 2005, 585)

Observamos nos exemplos seguintes cortes de trechos quer no meio da frase, como em (1) e (9), quer no fim, como em (8), (9) e 
(10), o que demostra, a falta de respeito pelo texto. Os efeitos da mutilação parcial destes fragmentos são evidentes: a ambiguidade em relação aos acontecimentos descritos pelo autor e a apresentação fragmentária do romance dos protagonistas. Não aparecem na edição de 1978 traduções de fragmentos em que Carlos da Maia refere o amor físico com a Maria Eduarda: naquela sala, quente ainda do seu amor em (7), as consequências psicológicas do incesto: o horror carnal um do outro em (8) ou trechos em que Ega reflecte sobre os eventos: dormindo com uma mulher que era sua irmã em (9), Carlos a dormir com a sua irmã em (10). Em (9) foi cortada a tradução da expressão e em camisa, uma referência à roupa interior da época, que sugeria a consumação do acto sexual.

(7) "Decerto era terrível tornar a vê-la naquela sala, quente ainda do seu amor, agora que a sabia sua irmã... (OM 2005 [1888], 661) // Desigur că-i venea nespus de greu s-o revadă acum, cînd știa că-i e soră..." (FM 1978, 614) // "Desigur că-i venea nespus de greu s-o revadă acum, în încăperea aceea, înfierbântată încă de dragostea lor, cînd știa că-i e soră...” (FM 2005, 613)

(8) "[...] ansiosos por irem esconder, no fundo de mosteiros distantes, o horror carnal um do outro? Não!” (OM 2005 [1888], 661) // "[...] numai să meargă să se ascundă în fundul unor mînăstiri îndepărtate? Nu!” (FM 1978, 614) // “[...] numai să meargă să ascundă în fundul unor mânăstiri îndepărtate oroarea carnală pe care o resimțeau unul față de celălalt? Nu!" (FM 2005, 613)

(9) "Então a ideia que Carlos estava àquela hora na Rua de $\mathrm{S}$. Francisco, dormindo com uma mulher que era sua irmã, atravessou-o com uma cruel nitidez, numa imagem material, tão viva e real, que ele viu-os claramente, de braços enlaçados, e em camisa...” (OM 2005 [1888], 633) // "Atunci gîndul că la ora aceea Carlos era desigur în Strada Francisc l-a străfulgerat cu o precizie crudă, ca o imagine materială, atât de vie și de reală, că i-a văzut limpede, îmbrățișați. (FM 1978, 587)" // "Atunci gîndul că la ora aceea Carlos era desigur în Strada Francisc l-a străfulgerat cu o precizie crudă, ca o imagine materială, atât de vie și de reală, că i-a văzut limpede, îmbrățișați, în cămașă.” (FM 2005, 586)

(10) Só sentia em torno de si, como flutuando no ar, aquele horror Carlos a dormir com a sua irmã. (OM 2005 [1888], 639) // "Simțea doar în jurul său, plutind parcă prin văzduh, oroarea aceea." (FM 1978, 593) // "Simțea doar în jurul său, plutind parcă prin văzduh, oroarea aceea: Carlos culcându-se cu sora sa." (FM 2005, 592) 
Identificámos também alguns cortes parciais relacionados com assuntos políticos. Talvez o mais interessante para o público romeno seja o exemplo (11), em que foi eliminada a referência à Roménia e à Bulgária num contexto potencialmente ameaçador para o "orgulho nacional". Uma comparação com países na altura muito longínquos do horizonte cultural do leitor português não passa neste contexto, na nossa opinião, de um mero artifício retórico do autor, mas os censores cortaram a expressão, talvez por não ser interpretada como julgamento de valor. Em 1978 a Roménia já se encontrava em plena fase de propaganda nacionalista, portanto as possíveis críticas à imagem idealizada do país deveriam ser eliminadas, como aconteceu neste caso.

(11) "Não tinham feitio, não tinham maneiras, não se lavavam, não limpavam as unhas... Coisa extraordinária, que em país algum sucedia, nem na Roménia, nem na Bulgária!” (OM 2005 [1888], 700) // "N-aveau ținută, n-aveau maniere, nu se spălau, nu-și curățau unghiile... Lucru nemaipomenit, care în nici o țară nu se mai întîlnea!" (FM 1978, 650) // "N-aveau ținută, n-aveau maniere, nu se spălau, nu-și curățau unghiile... Lucru nemaipomenit, care în nicio țară nu se mai întîlnea, nici în România, nici în Bulgaria!" (FM 2005, 650)

Em (12) foi suprimida a tradução do trecho pertence cá ao partido. Numa sociedade em que ser membro do Partido Comunista Romeno era obrigatório para conseguir uma casa, ser promovido na carreira, trabalhar na administração local ou central, em que as pessoas sabiam perfeitamente que o partido controlava a vida social e pessoal dos cidadãos, este trecho não podia passar despercebido. A identificação que o leitor romeno podia fazer com a realidade em que vivia era óbvia, razão pela qual os censores eliminaram o fragmento na edição de 1978.

(12) "É pelo Craveiro, que é bom rapaz, e demais a mais pertence cá ao partido! (OM 2005 [1888], 585) // Dar mi-e de Craveiro, care-i băiat de treabă, și, mai mult, e şi de-al nostru! (FM 1978, 542) // Dar mi-e de Craveiro, care-i băiat de treabă, și, mai mult, e și de-al nostru, din partid!" (FM 2005, 541)

Em (13), selecionámos um exemplo em que a supressão parcial de uma frase continua com omissões totais, de forma a se eliminar as considerações sobre a relação incestuosa. Ega questionase neste fragmento sobre o drama do protagonista; depois de saber que Maria Eduarda era sua irmã, Carlos da Maia sentiu a mesma atração por ela, cedeu e foi para a cama com ela pela última vez. Os fragmentos explícitos, evidenciados por nós em itálico, foram 
eliminados pelos censores, talvez por ilustrarem a chamada "degradação burguesa".

(13) "Sentia agora bem a tortura em que o pobre Carlos se debatera, sob o despotismo de uma paixão até aí legítima, em que numa hora amarga se tornava de repente monstruosa, sem nada perder do seu encanto e da sua intensidade... Humano e frágil, ele não pudera estacar naquele violento impulso de amor e de desejo, que o levava como num vendaval! Cedera, cedera, continuara a rolar àqueles braços, que inocentemente o continuavam a chamar. E aí anadava agora, aterrado, escorraçado, fugindo ocultamente de casa, passando o dia longe dos seus, numa vadiagem trágica, como um excomungado que receia encontrar olhos puros onde sinta o horror do seu pecado..." (OM 2005 [1888], 673)

"Simțea bine chinul în care se zbătea bietul Carlos... Și-l închipuia acum, îngrozit, descurajat, fugind într-ascuns de acasă, petrecânduși ziua departe de ai săi, hoinărind tragic... "(FM 1978, 624-625)

"Simțea bine chinul în care se zbătea bietul Carlos sub tirania unei pasiuni până atunci legitime, și care într-un moment de amărăciune devenise brusc monstruoasă, fără să-şi piardă nimic din farmec și din intensitate... Fïință omenească fragilă, el nu putuse să facă față acelui impuls violent al iubirii și dorinței, care-l purta ca un uragan! Cedase, cedase, continuase să se lase pradă acelor brațe care, în mod inocent, continuau să îl cheme la ele. Și-l închipuia acum, îngrozit, descurajat, fugind într-ascuns de acasă, petrecându-şi ziua departe de ai săi, hoinărind tragic ca un excomunicat care se teme să dea ochii cu sufletele curate în care să simtă oroarea de păcatul său..." (FM 2005, 624)

Há também exemplos de supressões integrais, ilustrativas para o modus operandi da censura comunista.

Supressões integrais

Por razões de espaço, não podemos apresentar a maior intervenção da censura, um corte integral de quase duas páginas no capítulo XVII, em que Carlos da Maia reflecte sobre o incesto, a repugnância física que sentia por Maria Eduarda. Trata-se dum trecho que se encontra nas páginas 674-676, na edição portuguesa do romance consultada por nós, cuja tradução em romeno aparece integralmente na edição de 2005, nas páginas 625-627.

A tradução de outros fragmentos, em que o protagonista se revoltava sobre o desejo que ainda sentia pela irmã - ver o exemplo (14) -, ou em que o narrador conta de maneira explícita a cena do incesto - ver a parte evidenciada por nós em itálico no exemplo (15) -, foram igualmente suprimidos na íntegra na edição de 1978. Mais uma vez, observamos a brutal mutilação do texto para o tornar mais 
"adequado" às normas morais defendidas pela propaganda do regime comunista romeno, que eliminava dos livros referências à sexualidade.

(14) "Assim estamos vivos, mas mortos um para o outro, e viva a paixão que nos unia!... Pois tu imagimas que por me virem provar que ela é minha irmã, eu gosto menos dela do que gostava ontem, ou gosto de um modo diferente? Está claro que não! O meu amor não se vai de uma hora para a outroa acomodar a novas circunstâncias, e transformar-se em amizade... Nunca! Nem eu quero! Era uma brutal revolta - o seu amor defendendo-se, não querendo morrer, só porque as revelações de um Guimarães e uma caixa de charutos cheia de papéis velhos o declaravam impossível, e lhe ordenavam que morresse!"(OM 2005 [1888], 656)

"Şi trăiește pasiunea care ne unea!... Păi tu crezi că dacă vine să-mi demonstreze că ea e sora mea, o s-o iubesc mai puțin decât am iubit-o ieri, sau s-o iubesc într-un alt fel? Bineînțeles că nu! Dragostea mea nu dispare de la o oră la alta ca să se potrivească noilor circumstanțe, și să se transforme în prietenie... Niciodată! Si nici nu vreau! Era o revoltă brutală, iubirea sa apărându-se, nevrând să moară, numai pentru că dezvăluirile lui Guimarães şi alte unei cutii de țigări pline cu hârtii vechi o declarau imposibilă, și-i porunceau să moară!" (FM 2005, 608)

(15) “- Achei-me tão cansada, depois de jantar, veio-me uma preguiça... Mas então partires assim de repente!... Que seca! Dá cá a mão! Ele tentava, procurando na brancura da roupa: encotrou um joelho, a que percebia a forma e o calor suave, através da seda leve: e ali esqueceu a mão, aberta e frouxa, como morta, num entorpecimento onde toda a vontade e toda a consciência se lhe fundiam, deixando-lhe apenas a sensação daquela pele quente e macia, onde a sua palma pousava. Um suspiro, um pequeno suspiro de criança, fugiu dos lábios de Maria, morreu na sombra. Carlos sentiu a quentura de desejo que vinha dela, que o entontecia, terrível como o bafo ardente de um abismo, escancarado na terra a sus pés. Ainda balbuciou: "Não, não...» Mas ela estendeu os braços, envolveu-lhe o pescoço, puxando-o para si, num murmúrio que era como a continuação do suspiro, $e$ em que o nome de «querido" sussurrava e tremia. Sem resistência, como um corpo morto que um sopro impele, ele caiu-lhe sobre o seio. Os seus lábios secos acharam-se colados, num beijo aberto que os humedecia. E de repente, Carlos enlaçou-a furiosamente, esmagando-a e sugando-a, numai paixão e num desespero que fez tremer todo o leito." (OM 2005 [1888], 667)

“- M-am simțit atît de obosită! După masă, m-a apucat o lene, rosti Maria. Dar de ce pleci așa de brusc?... (FM 1978, 619)

- M-am simțit atît de obosită! După masă, m-a apucat o lene, rosti Maria. Dar de ce pleci așa de brusc?... Ce plictiseală! Dă-mi mâna! 
El pipăia, căutând albeața capotului: a dat peste un genunchi, căruia îi percepea forma și căldura suavă, prin mătasea subțire; și şi-a uitat acolo mâna, desfăcută și fără vlagă, parcă moartă, întro toropeală în care orice voință și orice conștiință piereau, lăsându-i doar senzația acelei piei calde și mătăsoase, pe care îşi așezase palma. Un suspin, un mic suspin de copil i-a scăpat Mariei printre buze, pierind în întuneric. Carlos a simțit arsura dorinței pe care o emana ea, care-l amețea, teribil ca suflul arzător al unui abis, deschis la picioarele lui. A mai bâiguit încă: „Nu, nu...” Dar ea şi-a întins brațele, i-a înconjurat gâtul, trăgându-l spre ea, cu un murmur care era parcă o continuare a suspinului, și în care cuvântul „iubitule” susura și tremura. Fără să se împotrivească, precum un corp mort pe care îl împinge un suflu, s-a prăbuşit peste sânul ei. Buzele lor uscate s-au trezut unite, într-un sărut înfocat care le umezea. Şi, deodată, Carlos a înlănțuit-o cu furie, strivind-o şi sugând-o, cuprins de o pasiune şi o disperare care a făcut să tremure patul." (FM 2005, 618-619)

Outro trecho que não se encontra na edição romena d'Os Maias de 1978 mostra uma abordagem "politicamente correta" dos censores: foi eliminada a tradução dum parágrafo em que se faz uma crítica aos negros de São Tomé, que imitam de forma exagerada (e ridícula) os costumes europeus da época. Esta intervenção da censura justifica-se na medida em que na década dos '70 Ceauşescu queria fortalecer as relações económicas com a África, para aumentar as exportações do país. A Roménia tinha passado por um processo acelerado de industrialização, mas não conseguia competir com as empresas ocidentais, e queria conquistar diferentes mercados africanos. Vejamos o fragmento suprimido em português e a sua tradução integral, publicada na edição de 2005:

(16) "É o que sucede com os pretos já corrompidos de São Tomé, que vêem os europeus de lunetas - e imaginam que nisso consiste ser civilizado e ser branco. Que fazem então? Na sua sofreguidão de progresso e de brancura, acavalam no nariz três ou quatro lunetas, claras, defumadas, até de cor. E assim andam pela cidade, de tanga, de nariz no ar, aos tropeções, no desesperado e angustioso esforço de equilibrarem todos estes vidros - para serem imensamente civilizados e imensamente brancos..." (OM 2005 [1888], 712)

"Și ce se mai întâmplă și cu negrii deja corupți din São Tomé, care îi văd pe europeni cu ochelari, şi-şi închipuie că asta înseamnă să fii civilizat și alb. Așa că, ce fac? În lăcomia lor de progres și de albire, își pun călare pe nas trei, patru ochelari, albi, fumurii, chiar colorați. Şi umblă așa prin oraş, despuiați, cu nasul sus, împiedicându-se, făcând eforturi disperate şi speriate de a ține în echilibru toate sticlele acela (sic!) - ca să se simtă imens de civilizați şi imens de albi...” (FM 2005, 662) 


\section{A guisa de conclusão}

Eça de Queirós não beneficiou na Roménia de uma receção adequado. Conhecido por especialistas em literatura portuguesa (as crónicas de Mihai Zamfir na revista România Literară são um exemplo neste sentido), ou em literatura comparada (Rodica Grigore dedica-lhe um capítulo consistente no seu livro de 2008), Eça de Queirós é um "ilustre desconhecido" no espaço cultural romeno. Mircea Lăzăroniu (2007), que se debruça sobre as traduções romenas de Eça de Queirós sublinha que as obras do romancista português tiveram pouca divulgação junto dos leitores romenos. A edição de 2005 do romance Os Maias teve, sem dúvida, um propósito emendador; esta obra meceria uma versão integral em romeno. Sendo a Universal Dalsi, uma editora pequena, a vendas não foram muito consistentes.

Esta breve análise pontual, que se concentrou na apresentação dos mecanismos usados pela censura na tradução do romance Os Maias de Eça de Queirós, deveria ser continuada. Achamos que um processo mais amplo de restitutio ad integrum quer através da publicação dos fragmentos suprimidos, quer através da reedição das obras censuradas - seria desejável para dar ao público romeno a possibilidade de ler obras portuguesas nas suas versões integrais. Este estudo mostra também quão difícil era, durante um regime totalitário, a tarefa dos tradutores que se tornavam, sem querer, por causa da intervenção dos censores, em verdadeiros traidores do texto original.

\section{Abreviações \\ $\mathrm{OM}=$ Os Maias \\ $\mathrm{FM}=$ Familia Maia \\ Referências bibliográficas}

COROBCA, Liliana. "Instituțiile cenzurii în regimul comunist". Revista 22. 2013. Disponível online: http://revista22.ro/32615/.html [última consulta 30.10.2016]

COROBCA, Liliana. "Incursiune în cenzura sovietică (Glavlit), 1922-1991". Arhivele Totalitarismolui, No 74- 75, 1-2. 2012: 8-20.

GHIȚESCU, Micaela. "Traduire en Roumanie". TransLitterature. No 9. 1995: 55-58. Disponível online: http://www.translitterature.fr/media/article_125.pdf [última consulta 30.10.2016]

GHIȚESCU, Micaela. "Le traducteur littéraire et la censure communiste". In Alvaro Rochetti, Dragomir Costinean, Alain Vuillemin (eds.), La littérature contre la dictature en et hors de la Roumanie (1947-1989). Timişoara: Editions Hestia-Certel-Cirer, 1999: 171-174. 
GHIŢESCU, Micaela. "Destino de Eça de Queirós na Roménia através das traduções”. Revista Camões. No 9/10, 2000: 248-257.

GHIȚESCU, Micaela. Între uitare și memorie. București: Humanitas. 2012. GRIGORE, Rodica. Literatura universală şi comparată. Cluj-Napoca: Casa Cărții de Știință. 2008.

IONESCU, Arleen. "Un-sexing Ulysses: the Romanian translation "under" communism". Scientia Traductionis. 2010. No 8. Disponível online: https://periodicos.ufsc.br/index.php/scientia/article/view/19804237.2010n8p237 [última consulta 31.10.2016]

LAZĂROIU, Mircea. "Cronica traducerilor. Un anti-idealist: José Maria Eça de Queiroz". In România Literară. $\mathrm{n}^{0}$ 4, 2007. Disponível online: http://www.romlit.ro/un_anti-idealist_jos_maria_ea_de_queiroz [última consulta 30.10.2016]

RĂDULESCU, Anda. "Escamotage des tabous dans la traduction en roumain des récits français pour enfants au nom d'un idéal communiste". In Michel Ballard (ed.) Censure et traduction. Arras: Artois Presses Université. 2011: 317-328.

TAVARES RODRIGUES, Urbano. Nesupuşii. Sfirş̧it de exil. București: Editura Univers. 1987.

TISMĂNEANU, Vladimir (coord). Raport Final. Comisia Prezidenţială pentru Analiza Dictaturii Comuniste din România. 2006. Disponível online: https://www.wilsoncenter.org/sites/default/files/RAPORT\%2OFINAL_\%2 oCADCR.pdf [última consulta 30.10.2016]

VIDA, Raluca. "De la censure officielle à l'" autocensure " dans les retraductions de Madame Bovary en roumain". In Michel Ballard (ed.) Censure et traduction. Arras: Artois Presses Université. (2011): 305-316.

ZAMFIR, Mihai. "Scrisori portugheze: Eça de Queirós (I)". In România Literară. $\quad \mathrm{n}^{\mathrm{O}} \quad 43, \quad 2000$. Disponível online: http://www.romlit.ro/ea_de_queirs_i [última consulta 30.10.2016]

ZAMFIR, Mihai.“Scrisori portugheze: Eça de Queirós (II)”. In România Literară. $\quad \mathrm{n}^{0} \quad 45, \quad 2000 . \quad$ Disponível online: http://www.romlit.ro/ea_de_queirs_ii [última consulta 30.10.2016]

ZAMFIR, Mihai. "Scrisori portugheze: Eça de Queirós (III)". In România Literară. $\quad \mathrm{n}^{\mathrm{0}} \quad 47, \quad 2000 . \quad$ Disponível online: http://www.romlit.ro/ea_de_queirs_iii [última consulta 30.10.2016] ZAMFIR, Mihai. "Scrisori portugheze: Eça de Queirós (final)". In România Literară. $\quad \mathrm{n}^{\mathrm{O}} \quad 49, \quad 2000 . \quad$ Disponível online: http://www.romlit.ro/ea_de_queirs_final [última consulta 30.10.2016] ZAMFIR, Mihai. "Scrisori portugheze: Eça de Queirós (post scriptum)". In România Literară. $\mathrm{n}^{0} \quad 51-52, \quad 2000$. Disponível online: http://www.romlit.ro/ea_de_ queirs_post_scriptum [última consulta 30.10.2016]

ZAMFIR, Mihai. "Eça de Queirós - ultima întruchipare”. In România Literară. $\quad \mathrm{n}^{\mathrm{o}} \quad 3, \quad 2006 . \quad$ Disponível online: http://www.romlit.ro/ea_de_queirs_-_ultima_ntruchipare [última consulta 30.10.2016]

ZAMFIR, Mihai. “Actualitatea: Eça de Queirós şi I.L. Caragiale”. In România Literară. $\quad \mathrm{n}^{\mathrm{o}} \quad 24, \quad 2014$. Disponível online: 
http://www.romlit.ro/ea_de_queirs_ i_i.l._caragiale [última consulta 30.10.2016].

\section{Corpus}

MACHADO, Dinis.

Ce spune Molero. Trad. Micaela Ghițescu. București: Editura Univers.1981.

Ce spune Molero. Trad. Micaela Ghițescu. București: Humanitas. 2005.

QUEIROZ, Eça de. Crima părintelui Amaro. Trad. Micaela Ghițescu. București: Editura pentru Literatură Universală. 1968.

Relicva. Trad. Micaela Ghițescu. București: Editura Univers. 1972.

Familia Maia. Trad. Micaela Ghițescu. București: Editura Univers. 1978.

Vărul Bazilio. Trad. Micaela Ghițescu. București: Editura Univers. 1983.

Oraşul și muntele. Trad. Mioara Caragea. București: Editura Univers. 1987.

Familia Maia. Trad. Micaela Ghițescu. București: Editura Universal Dalsi. 2005.

RUBEN A. Singurătate în patru. Trad. Micaela Ghițescu. București: Editura Univers. 19990.

SARAMAgO, José. Memorialul de la Mafra. Trad. Mioara Caragea. București: Editura Univers. 1988.

Memorialul mînăstirii. Trad. Mioara Caragea. Iași: Polirom. 2007. 